\title{
SABERES DA HISTÓRIA DA EDUCAÇÃO FÍSICA EM PRESIDENTE PRUDENTE: DESFILE ESCOLAR UMA TRADIÇÃO DE PRÁTICAS PEDAGÓGICAS (1937-1971)
}

\author{
Jaqueline Costa Castilho Moreira \\ Universidade Estadual Paulista - UNESP, Departamento de Educação Física, Presidente Prudente, SP. E-mail: \\ jaqueline.castilho@unesp.br.
}

\section{RESUMO}

Os desfiles comemorativos são expressões culturais festivas trazidas pelos europeus, que ganharam vulto no Brasil. Todavia, em governos ditatoriais tornou-se uma prática pedagógica obrigatória, que encerrava em seu ideário um programa de educação cívica associado a políticas centralizadoras de nacionalização. Objetivando investigar os "desfiles escolares" como uma tradição de prática docente entre 1937-1971; a metodologia perpassa por uma abordagem historiográfica, centrada em pesquisa documental e bibliográfica, baseada em formulações identificadas como "História Cultural". O estudo apresenta duas categorias de resultados: um plano de ensino do "desfile como conteúdo" de um curso Normal de currículo oficial, e a segunda refere-se aos "desfiles como tradição" de duas escolas de Presidente Prudente. Este levantamento evidencia a relação direta entre essas apresentações públicas e a valorização identitária das escolas perante a sociedade local, o que também tornava os saberes da Educação Física enaltecidos pelo menos durante o evento.

Palavras-chave: cultura, nacionalismo, identidade, pertencimento, Curso Normal.

\section{HISTORY KNOWLEDGE OF PHYSICAL EDUCATION IN PRESIDENTE PRUDENTE: SCHOOL PARADE A TRADITION IN PEDAGOGICAL PRACTICES (1937-1971)}

\begin{abstract}
The celebratory parades are festive cultural expressions brought by the Europeans, who have gained importance in Brazil. However, in dictatorial governments it became an obligatory pedagogical practice, which contained in its ideals a program of civic education associated with centralizing policies of nationalization. Aiming to investigate "school parades" as a tradition of teaching practice between 1937-1971; the methodology runs through a historiographical approach, centered on documentary and bibliographic research, based on formulations identified as "Cultural History". The study presents two categories of results: a teaching plan of the "parade as content" of a Normal course of official curriculum, and the second refers to "parades as tradition" of two schools of Presidente Prudente. This survey evidences the direct relationship between these public presentations and the identity valorization of the schools before the local society, which also made the knowledge of Physical Education exalted at least during the event.
\end{abstract}

Keywords: culture, nationalism, identity, belonging, Normal Course. 


\section{INTRODUÇÃO}

Desfilar designa o ato de marchar em filas. Os desfiles comemorativos são expressões culturais festivas trazidas pelos europeus, que ganharam vulto no Brasil. No período 1930-40, durante o governo de Getúlio Vargas, os desfiles e as festas cívicas tornaram-se ações de um programa político-social de educação cívica, que incentivava a construção de um ideário de nação e inculcava na memória coletiva, por meio das solenidades simultaneamente ocorridas em todo o país, representações da identidade nacional brasileira.

Vale lembrar que, as políticas de nacionalização de Vargas, buscavam "erradicar as minorias étnicas, linguísticas e culturais, atuando sobre os núcleos de colonização estrangeira" (SOUZA, 2008, p. 72). Visando estabelecer unidade e homogeneidade no território nacional, combatendo particularidades regionais especialmente em locais com alta densidade de imigrantes; a política autoritária e centralizadora de Vargas também chegou a Presidente Prudente e Alta Sorocabana, região afastada da capital paulista e com forte imigração oriental.

Para colocar em prática este ideário, os governos ditatoriais usaram algumas estratégias. Norteados por princípios de demonstração pública de disciplina e treinamento, caráter cívico, atitude de solenidade e respeito aos símbolos nacionais pelos estudantes. $\mathrm{O}$ ritual que envolvia o "desfilar" evocava abstrações simbólicas, com o estabelecimento de feriado nacional; o hasteamento da bandeira; a entoação do hino nacional; o uso de vestimentas específicas impecáveis; o encadeamento da percussão e da música, produzindo alternância nos estados emocionais dos presentes, além da integração com o coletivo. A disseminação das práticas dos desfiles foi incentivada pelo ideário de se constituir uma nação pela Educação, empreendimento assumido por boa parte do magistério. Fonte de silenciosa doutrinação, tanto os docentes envolvidos com a formação como aqueles em exercício foram também convencidos a cumprir seu papel de semeadores de valores cívicos e patrióticos.

Além dos elementos de convencimento citados anteriormente acrescentam-se dois outros relacionados à área da Educação Física. O engajamento dos professores da área era justificado não somente pela inspiração militarista das ginásticas praticadas nas aulas de grandes escolas; apregoava-se o higienismo, o sanitarismo e o eugenismo como componentes necessários ao desenvolvimento de uma "nação forte", da qual esses docentes também eram responsáveis. $E$ uma segunda forma de persuasão era de que os desfiles propiciavam uma formação cultural, por propiciarem apreciação estética aos participantes e expectadores das demonstrações. Essa era possível, graças ao trabalho pedagógico de todo um período letivo do professor de Educação Física, que se encerrava com a exposição pública de evoluções coreográficas feitas com virtuosidade por alunos selecionados; concretizando o êxito do ideário de disciplina, ordem e prontidão, na sincronia de um exército de escolares marchando para um melhor futuro da pátria.

A proximidade da formação dos educadores físicos com a formação de normalistas (MOREIRA, 2013), desde a Reforma de Fernando Azevedo em 1928, refletiu-se no repertório de conhecimentos, saberes, habilidades, códigos e valores, relacionados ao modelo de homem e cidadão forjados no contexto dos dois períodos do governo de Vargas. Pela necessidade de que uma educação moral, cívica e corpórea estivesse presente nas atividades e circunstâncias pedagógicas que envolviam estar fora dos "muros da escola", esse tipo de saber foi amplamente disseminado. Assim, houve grande incentivo, em conjunto com uma eficaz fiscalização empreendida pela Divisão de Educação Física (DEF) dos desfiles como prática educativa das escolas das cidades brasileiras. Perante este cenário, buscou-se o entendimento sobre as razões pelas quais esse tipo de evento comemorativo foi sustentado como um legado pedagógico datado, capaz de referenciar a identidade de um grupo/escola e de levar comoção à uma determinada sociedade. Assim, este estudo objetivou investigar os "desfiles escolares" como uma tradição de prática pedagógica docente, entre 1937-1971. 


\section{MÉTODO}

A partir de uma abordagem historiográfica, centrada em pesquisa documental e bibliográfica, o estudo baseou-se em formulações identificadas como "História Cultural". Segundo Chartier (1990, p. 16): “a história cultural tem por princípio objeto identificar o modo como em diferentes lugares e momentos uma determinada realidade social é construída, pensada, dada a ler". E por que não expressa corporalmente? Para este autor, as representações que são construídas pelo mundo social, mesmo que almejem alcançar a universalidade de uma racionalização científica, são sempre determinadas pelos interesses do grupo que as forjam. Para lidar com o contraponto é necessário relacionar os discursos proferidos com a posição de quem os realiza. Assim, os discursos gerados não são neutros. Muito pelo contrário produzem estratégias e práticas (sociais, políticas ou escolares), que tendem a impor uma autoridade à custa de outros por elas menosprezados, ou a legitimar um projeto reformador ou ainda, justificar escolhas e condutas.

A busca por documentos que pudessem trazer a luz "os desfiles escolares", como objeto de investigação foi realizada na cidade de Presidente Prudente (SP). Acreditou-se que este contexto investigativo possibilitasse um diálogo glocal capaz de "reconhecer nas situações mais locais as interdependências que as ligam ao longe" (CHARTIER, 1990, p.57), ou em outras palavras, em um contexto geral; já que os desfiles escolares eram lições praticadas nas escolas de todo o Brasil, como forma de estimular o civismo, o sentido de integração e identidade nacionais. Optou-se pela periodização entre 1937-1971, por apresentar importantes pontos de inflexão. O ano de 1937 foi o momento em que Vargas assumiu o poder após a Revolução de 1930, iniciando seu governo ditatorial com o fechamento do Congresso Nacional e instalação do Estado Novo. E 1971, por ser o ano das reformas do ensino de primeiro e segundo grau promulgadas pelo Decreto Lei 5.692.

De uma forma geral, o presente estudo inseriu-se em um campo que privilegiou os documentos citados como fontes e como objetos de pesquisa; havendo ainda a necessidade de articulá-los às fontes secundárias e prescrições adotadas pelas políticas educacionais, para que fizessem sentido. Em relação à análise foram feitas leituras, visando à identificação, diferenciação e compreensão da problemática, com posterior interpretação a partir de referenciais da História Cultural (CHARTIER, 1990; SOUZA, 2008) e da literatura local (ABREU, 1972; RIBEIRO, 1999; RESENDE, 1992, 2006).

\section{RESULTADOS}

Embora não houvesse avaliação das práticas educativas da Educação Física nas décadas de 1930-70, o processo de apreciação de seu ensino, da verificação dos progressos alcançados e de seu próprio valor associado diretamente a imagem da instituição escolar a que servia, era muito mais contundente, ao ser aferido pela comunidade, nas exposições públicas das escolas. A fruição do movimento ensinada e aprendida pelos escolares era observada nas demonstrações propiciadas nos desfiles cívicos. Nesta perspectiva, o estudo apresenta duas categorias de resultados: a primeira discrimina as progressões práticas para realização de um desfile cívico, por meio de plano de ensino extraído da fonte primária Caderno do Normal (1964), manuscrito pertencente a uma aluna normalista da década de 1960, matriculada em curso de currículo oficial para esta formação. A segunda categoria refere-se aos desfiles realizados pelas escolas de Presidente Prudente.

\section{Desfiles como conteúdo}

Por sua obrigatoriedade, os cursos normais instrumentalizavam docentes para que realizassem este tipo de apresentação escolar dentro da ótica pedagógica da época: os "métodos de ensino". Um destes encontra-se transcrito a seguir, com instruções e os procedimentos para realização da apresentação com público de grande vulto: 
PLANO DE AULA DE DESFILE

(Serve para todos os graus, só deve mudar a idade e a duração)

REGIME DA LIÇÃO

Idade: 9 a 11 anos - Duração: 20 a 25 minutos - Processo: Desfile

Local: Pátio do colégio - Material: Não precisa - Uniforme: Diário

Horário: 8 horas.

DESENVOLVIMENTO

I Parte: Formar coluna por um, por altura, e ensinar todas as posições necessárias: Cobrir (elevar os dois braços estendidos para frente colocando-os nos ombros do colega da frente); Posição fundamental (calcanhares unidos, pontas dos pés separadas, braços junto ao corpo, dedos unidos, mãos em formato de concha, ombros para trás, abdômen retraído, cabeça erguida, olhando para frente); Descansar (com afastamento lateral da perna esquerda, ombros para trás, braços com mãos cruzadas para trás, peso do corpo distribuído em ambas as pernas); Marcar passo no lugar (elevar o joelho alternado, iniciando com o joelho esquerdo, depois o direito, com batida forte do pé esquerdo); Movimento dos braços (movimentar os braços lateralmente, iniciando com o braço direito à frente e com o esquerdo atrás, mão em formato de concha); Movimentos dos braços e pernas (combinar o movimento de braços com as pernas, iniciando a marcha com o movimento do braço direito a frente, marcado com a perna esquerda); Alto( a voz de comando Alto é dada no pé esquerdo, depois conta um com o pé direito, dois com o pé esquerdo e três, juntando o pé direito com o esquerdo, no lugar).

II Parte: Marchar normal; Marcar passos com movimento de braços e Alto. Formar coluna por três e por quatro, e ensinar o "Peão".

III Parte: Marchar normal e Alto em marcha. Marchar com canto (Hino a Bandeira). Exercícios de Ordem Unida (direita, esquerda, meia volta volver, um passo à direita, um passo à esquerda, um passo à frente, um passo á retaguarda). Descansar. Fora de forma.

Mesmo que no plano exposto houvesse os indicativos de especificidades, como a explicitação da faixa etária; na preparação dos alunos, as posições fundamentais, as vozes de comando e os exercícios de ordem unida na prática, eram iguais para todos os alunos da escola, sem distinção.

\section{Desfiles como tradição}

Seguindo o pressuposto que os cursos normais e secundários (neste estudo dois ginásios de Presidente Prudente) indiciassem conhecimentos além da ginástica nas aulas de Educação Física; este estudo considerou as apresentações dos alunos em momentos cívicos como saberes docentes para formação e exercício na área; perscrutando registros desses eventos em duas escolas prudentinas.

- O Gynásio/Colégio São Paulo

Fundado em 1930 pelo $\operatorname{Dr}$ Boulanger Uchoa, esta escola particular foi batizada como Ginásio São Paulo, embora não ministrasse esse tipo de ensino em sua fundação. Iniciou com um curso propedêutico de três anos que possibilitava como sequência o curso de Guarda-livros de dois anos. Por formar profissionais para escrituração mercantil, a unidade passou a ser chamada de Academia de Comércio do Ginásio São Paulo (ABREU, 1972). Após sete anos de sua abertura é que realmente a instituição passou a ofertar o curso ginasial, com duração de cinco anos, formando sua primeira turma com 18 alunos, no ano de 1941 (ABREU, 1972).

De 1939 a 1945 a instituição pertenceu a Colônia Japonesa, tendo inserido em seu currículo o ensino do idioma de origem natal. Resende (2006) não clarifica as razões da alteração da direção, apenas aponta que a unidade, novamente retoma o nome Ginásio São Paulo, foi arrendada por um grupo de professores, dentre eles: José Machado de Abreu, Hugo Miele, Floriza 
Dincao e Maria Luiza Bastos. Nesse momento, o Ginásio São Paulo (RESENDE, 2006, p. 177), disponibilizava os seguintes cursos: primário, ginasial e a Escola Técnica de Comércio, concorrendo em termos de oferecimento de vagas com a Academia de Comércio Dr. Joaquim Murtinho.

Figura 1. Desfile cívico em frente ao Gynásio São Paulo

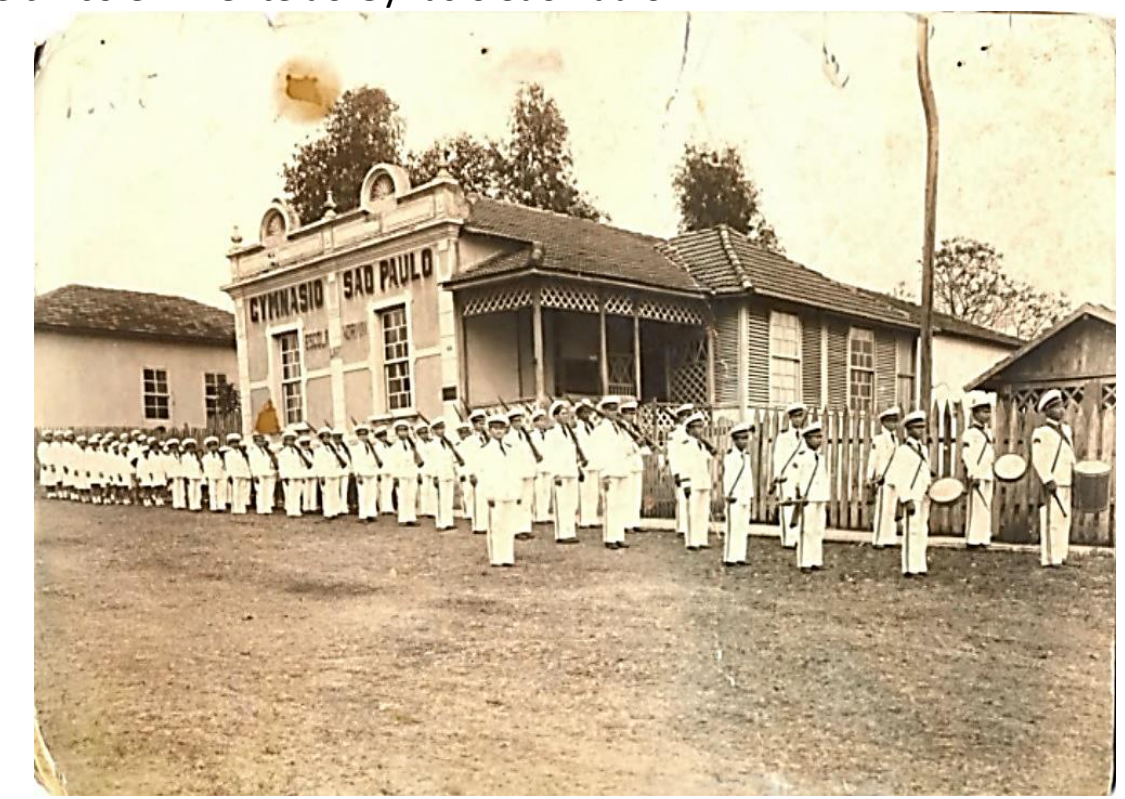

Fonte: Museu e Arquivo Municipal, sem data.

No ano de 1946, como primeiro diretor da nova fase da instituição José Machado de Abreu, professor de Educação Física, intencionando dar maior visibilidade a unidade e a nova direção anunciava frequentemente a escola no jornal "O Imparcial". Apelidado de Machadão foi um entusiasta das apresentações escolares promovendo desfiles cívicos e apresentações da fanfarra da instituição junto com o Instituto Educacional Fernando Costa (IE) e com o Colégio vocacional Cristo Rei.

- O Instituto de Educação Fernando Costa

As reivindicações populares em favor da melhoria de oferta em educação pública secundária aconteceram em diversas cidades brasileiras. Dentre essas, destacam-se os movimentos pró-ginásio (PILETTI, 1995, SOUZA, 2008; MOREIRA, 2013) manifestando o ideário republicano de enaltecimento da Educação como forma de ascender socialmente e minimizar a grande diferenciação entre o padrão de existência das classes sociais no país.

Considerada ao final de 1930, como capital da Alta Sorocabana (ABREU, 1972), ou ainda polo regional do oeste paulista (RIBEIRO, 1999, p. 102), Presidente Prudente foi uma dessas cidades que mobilizou sua população para requerer uma estrutura educacional pública que desce continuidade ao ensino primário.

Enfocando a possibilidade de continuidade dos estudos para outro nível de ensino, a intenção do movimento pró-ginásio iniciado em 1939 somente ocorreu durante a atuação de Adhemar de Barros como interventor federal do Estado de São Paulo, quando autorizou a criação do primeiro ginásio estadual na cidade, por meio do decreto-lei no 11.864 , em 11 de março de 1941. Entretanto, o interventor exigiu uma contrapartida do município; que Prudente contribuísse com verbas públicas para a construção do prédio que abrigaria o ginásio público. Essa situação mobilizou a comunidade local que levantou fundos por meio de quermesses e festas realizadas em grande estilo com participação da população.

Concretizado durante a gestão do prefeito Domingos Leonardo Cerávolo (RIBEIRO, 1999, p. 97), o ginásio estadual público recém-inaugurado atendeu 45 alunos em uma 1a série (ABREU, 
1972), e em uma perspectiva mais ampla, serviu a um amálgama de interesses que extrapolavam a demanda social por escolarização visando o mundo do trabalho. Estes oscilavam entre as intencionalidades políticas diante da situação geográfica interiorizada do município em relação à capital e, a crescente urbanização da cidade com aumento populacional, de renda e autonomia e com estes, novas reivindicações.

No ano de 1942 foi entregue a primeira parte da edificação do ginásio público e a segunda, em 1954 (RIBEIRO, 1999, p. 106). No ano de 1944 passou a funcionar no prédio do Ginásio, o Colégio Universitário (RIBEIRO, 1999, p. 113) criado pelo Decreto $n^{\circ} 13.543$ de 1943, no governo de Fernando Costa. A escolha de Presidente Prudente como sede deste curso teve grande repercussão na região, pois ele possibilitava a transposição dos alunos para graus superiores de ensino. No jornal "O Imparcial" há uma série de notícias que mostram o falecimento trágico de Fernando Costa (Interventor federal do Estado de São Paulo entre 1941- 45), a comoção da cidade e a homenagem que o tornou patrono da instituição em 1946. Ainda nesta fonte existem notícias sobre projeto para transformação do "Colégio e Escola Normal" para Instituto, desencadeado em 1952. Como não houve andamento, o jornal relata que em 11 de agosto de 1953 foi apresentado pelo deputado Péricles Rolim, o projeto de lei no 871 solicitando a transformação para Instituto de Educação Fernando Costa, o que aconteceu em 20 de outubro do mesmo ano, por meio da promulgação da Lei Estadual no 2.337/1953.

Figura 2. Desfile do Instituto Educacional Fernando Costa, carinhosamente conhecido na cidade como "IE".

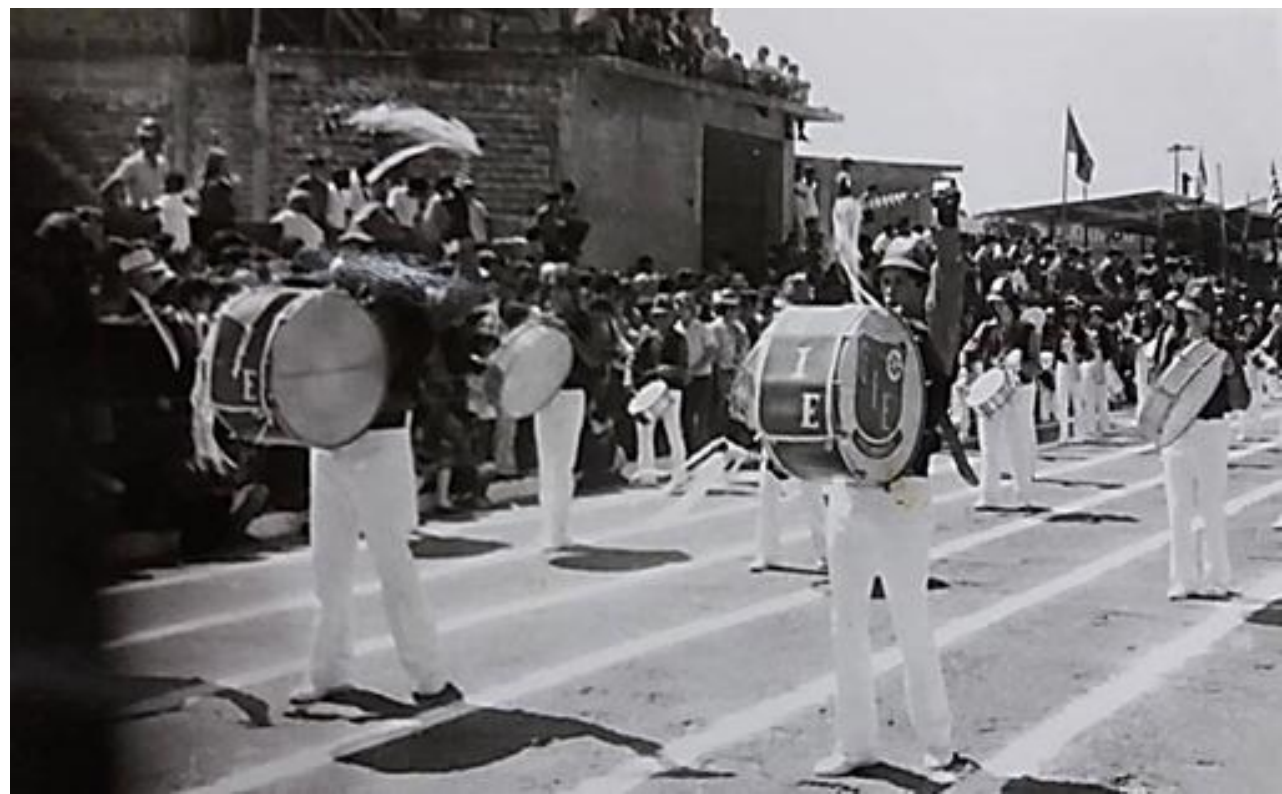

Fonte: Acervo pessoal da Profa. Daise Suelli Aguiar Alia Borelli. Sem datação.

O IE oferecia cursos de aperfeiçoamento e especialização em pré-primário, tinha infraestrutura diferenciada na região e por tanto, segundo Ribeiro (1999, p. 119) "era natural que a população quisesse seus filhos estudando no estabelecimento". Essa "promoção" para Instituto exigiu novas adequações também do professorado, como uma qualificação docente diferenciada, que passava por rigoroso crivo no momento de contratação. Os professores do curso normal do IE eram originários de outras cidades (RIBEIRO, 1999; RESENDE, 2006), muitos formados pela USP por meio do Curso de Formação de Professores Secundários (RIBEIRO, 1999, p. 112). Em 1976, a instituição deixou de ser Instituto de Educação para tornar-se Escola Estadual de Segundo Grau (RIBEIRO, 1999, p. 111).

No período entre 1940-50, fazia parte do currículo dos ginásios, o oferecimento da Educação Física, prática educativa obrigatória para todos os alunos até 21 anos, o que era também 
seguido aqui na região (RIBEIRO, 1999, p. 114). Até meados da década de 1970, as legislações federais e estaduais referiam-se à Educação Física como "prática educativa". No caso do IE, a prática educativa ficou sob a regência dos professores Lélia de Barros Castro (Educação Física Feminina) e Nilo Magalhães Ribeiro (Educação Física Masculina), sendo ministrados no ginásio: Bola ao Cesto, Ginástica, Atletismo, Futebol e Vôlei.

Na transição 1950-60 houve uma superlotação da escola, necessitando de que a instituição solicitasse ao Estado, a abertura de salas em outros prédios, utilizando salas ociosas de vários grupos escolares em determinados períodos, ou seja, "Extensões" (RIBEIRO, 1999, p. 119). Inferese que uma vicissitude semelhante tenha ocorrido com a Educação Física, pois um espaço mesmo que improvisado atende em um período letivo, um número delimitado de estudantes. Com as "Extensões", as dificuldades para que as aulas de Educação Física fossem ministradas também aumentaram, já que o número de estudantes foi amplificado, o que não foi acompanhado em termos de estruturas.

\section{DISCUSSÃO}

Embora de caráter obrigatório, sustentados por prescrições oficiais e pelo currículo oficial, como recuperado com a fonte Caderno do Normal (1964), os desfiles fizeram parte de ações que conclamavam o magistério a servir à pátria como destino e missão, fazendo desse "inculcamento" cívico, justificativa de um trabalho mal remunerado, mas relevante socialmente (SOUZA, 2008).

Também a celebração das datas comemorativas e cívicas foram momentos desencadeadores de competições entre as instituições de ensino particular e pública quanto a estética, a performance e a ousadia demonstradas em ornamentações exóticas, carros alegóricos, fanfarras com toques e batidas de percussão, coreografias e evoluções ginásticas e performáticas(RESENDE, 2006). Essas disputas revelavam outra forma de sustentação para os desfiles, aquele incentivado pelo pertencimento a um coletivo, expresso por signos identitários, no caso a "torcida" por uma das escolas.

O estudo revelou que essas apresentações públicas eram eventos aguardados pela sociedade prudentina, assumindo ainda conotações sociais e culturais importantes:

Sem televisão, a cidade girava em torno das festas promovidas pelas escolas e, principalmente, preparavam-se para os desfiles de sete e catorze de setembro, datas máximas da nacionalidade e da fundação do município... (RESENDE, 2006, p.132)

Para Chartier (1990, p.20), os desfiles como representações possuem caráter dúbio, de presença e de ausência, manifestando tensão:

Por um lado, a representação como dando a ver uma coisa ausente, numa distinção radical entre o que se representa e o que é representado; e por outro lado, a representação como exibição de uma presença, como apresentação pública de algo ou de alguém.

No sentido das ausências, por trás da aparência do resultado final desses eventos, existiam outros processos como o engajamento de sujeitos do âmbito educacional e fora dele, em uma atividade da qual para estes não havia nenhum tipo de remuneração ou contrapartida, embora sem estes não houvesse celebração. A imposição de autoridade à custa de outros por elas menosprezados (CHARTIER, 1990) é temática que merece aprofundamento de investigação, não cabendo na brevidade deste texto.

Na década de 1980, o entusiasmo com estas apresentações foi sendo reduzido. A marcha, anteriormente obrigatória a todos os escolares passou a ser facultativa, e com a redemocratização em 1988, este tipo de evento caiu no esquecimento. 


\section{CONCLUSÃO}

Nas décadas de 1930-70, os desfiles eram considerados fatos relevantes das cidades a serem noticiados pelos jornais locais, que na perspectiva de coleção e guarda como arquivo (modernamente banco de dados) colaboraram com o registro desse tipo de manifestação escolarizada da corporeidade. Vale lembrar que os saberes da Educação Física deste período, transmitidos pelos professores da época volatilizavam-se na oralidade dos comandos e da exibição momentânea das práticas performáticas, pois registros imagéticos por meio de fotografias ou de filmagens exigiam equipamentos de tecnologia dispendiosa e com acesso bastante restrito a população.

Este levantamento evidencia que as apresentações e seus resultados refletiam diretamente em uma valorização identitária da escola perante a sociedade local, o que também tornava o trabalho dos professores da Educação Física visível pelo menos durante o desenrolar do evento.

\section{REFERÊNCIAS}

ABREU, D.S. Formação histórica de uma cidade pioneira: Presidente Prudente. Presidente Prudente: Faculdade de Filosofia, Ciências e Letras de Presidente Prudente, 1972.

CHARTIER, R. A História cultural: entre práticas e representações. Trad. M. Galhardo, . Rio de Janeiro: Bertrand Brasil, 1990.

MOREIRA, J. C. C. Saberes em campo: a configuração do ensino escolar da Educação Física no Estado de São Paulo (1964-1985). 2013. 321 f. Tese (doutorado) - Universidade Estadual Paulista Júlio de Mesquita Filho, Faculdade de Ciências e Letras de Araraquara, 2013. Disponível em: http://www.athena.biblioteca.unesp.br/exlibris/bd/bar/33004030079P2/2013/moreira_jcc_dr_ar afcl.pdf>. Acesso em 03 ago. 2018.

PILETTI, N. História da Educação no Brasil. São Paulo: Ática, 1995.

RIBEIRO, A.I.M. Subsídios para a História da Educação de Presidente Prudente: as primeiras instituições escolares. São Paulo: Clíper Editora, 1999. 144 p.

RESENDE, B. Raízes Prudentinas. São Paulo: SENAC, 1992.

RESENDE, B. Raízes Prudentinas 2. Presidente Prudente: Ed. do autor, 2006.

SOUZA, R.F. História da organização do trabalho escolar e do currículo no século XX: ensino primário e secundário no Brasil. São Paulo: Cortez, 2008.

\section{FONTES}

Acervo iconográfico Profa. D.S.A.A.B. (sem datação- provável década de 1970). Instituto Educacional Fernando Costa. Presidente Prudente, SP.

Acervo particular Profa. R. F. C. (1964). Caderno do Normal. São Vicente, SP.

Acervo iconográfico e Coleção de exemplares do Jornal "O Imparcial" - 1930-1970, do Museu e Arquivo Histórico Municipal Prefeito Antônio Sandoval Netto. 